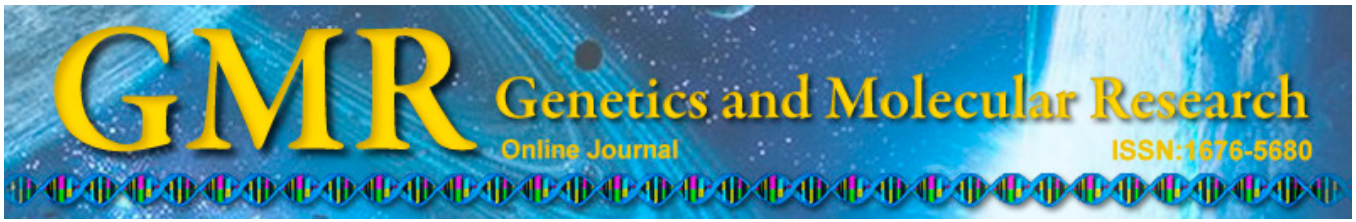

\title{
Development of novel polymorphic microsatellite markers for the blood clam Tegillarca granosa by pyrosequencing
}

\author{
Y.H. Dong, H.H. Yao, S.F. Shi, Y.B. Bao and Z.H. Lin \\ Zhejiang Key Laboratory of Aquatic Germplasm Resources, \\ College of Biological and Environmental Sciences, \\ Zhejiang Wanli University, Ningbo, China \\ Corresponding authors: Z.H. Lin / H.H. Yao \\ E-mail: zhihua9988@126.com / yaohanhan1020@126.com
}

Genet. Mol. Res. 14 (3): 8977-8987 (2015)

Received January 12, 2015

Accepted May 8, 2015

Published August 7, 2015

DOI http://dx.doi.org/10.4238/2015.August.7.6

\begin{abstract}
Large amounts of expressed sequence tags (ESTs) generated using next-generation sequencing technologies provide a cost-effective and valuable genomic resource for the development of microsatellite markers. In this study, we isolated 115 novel polymorphic microsatellite markers for the blood clam Tegillarca granosa from ESTs in 454 sequencing data. All the loci were characterized in 30 individual clams from a natural population in Xiangshan (Zhejiang Province, China). The number of alleles per locus varied from 2 to 10 , with an average of 3.78. The observed and expected heterozygosities ranged from 0 to 1 and from 0.040 to 0.799 , respectively. The polymorphic information content (PIC) ranged from 0.038 to 0.825 , and 29 highly polymorphic loci (PIC $\geq 0.5$ ) and 42 moderately polymorphic loci $(0.25<$ PIC $<0.5)$ were identified. Thirty-eight of the 115 loci deviated significantly from the Hardy-Weinberg equilibrium $(\mathrm{P}<0.01)$ after a Bonferroni correction. A BlastX search revealed that $46(40 \%)$ of the polymorphic loci identified were from transcript regions of known genes. The microsatellite markers developed in the present study
\end{abstract}


will greatly enrich the microsatellite resources of $T$. granosa, and are available for further population genetic analysis, genetic trait mapping, and molecular-assisted selection.

Key words: Tegillarca granosa; Microsatellite; Polymorphic marker; Pyrosequencing

\section{INTRODUCTION}

The blood clam Tegillarca granosa L. is found in the Indo-West Pacific, from east Africa to Polynesia, north to Japan, and south to northern and eastern Australia. Its delicious taste and high nutritional value have made it a popular seafood, and it has been extensively farmed along the coasts of southern China and several southeast Asian countries. Although it is a commercially important maricultured species, there have been few genetic studies of $T$. granosa because of a paucity of effective molecular markers.

Microsatellite markers, also known as single-sequence repeats (SSRs), are one of the most powerful genetic tools available, and have been widely applied in diversity analysis, genetic mapping, association studies, and marker-assisted selection (MAS) (Duran et al., 2009). Although over 100 SSRs have been characterized in T. granosa to date (Gu et al., 2008; Liu et al., 2012; Dong et al., 2012, 2013; Zhou et al., 2013), the development of multi-allelic SSRs is currently inadequate for studies of genetic connectivity and genetic mapping.

Large T. granosa sequence data sets derived from large-scale expressed sequence tag (EST) discoveries have recently enabled the mining of SSRs (Dong et al., 2012). These EST-SSR markers are inexpensive, labor-saving, and are frequently associated with annotated genes. In the present study, we developed 115 validated polymorphic EST-SSR markers in $T$. granosa using deep transcriptome sequencing, which will be useful for future studies of this species in terms of its conservation genetics, evolutionary studies, and molecular breeding.

\section{MATERIAL AND METHODS}

\section{Sample collection and DNA extraction}

Thirty T. granosa individuals were collected from Xiangshan, Zhejiang Province, China $\left(29.21^{\circ} \mathrm{N}, 121.46^{\circ} \mathrm{E}\right)$. The adductor muscles of all the samples were dissected and immediately preserved in alcohol at $-20^{\circ} \mathrm{C}$.

Total genomic DNA was extracted from the adductor muscles by standard proteinase $\mathrm{K}$ digestion, phenol-chloroform extraction, and ethanol precipitation. The quality and concentration of DNA were examined using $1.2 \%$ agarose gel electrophoresis and the $\mathrm{OD}_{260} / \mathrm{OD}_{280}$ ratio, using a NanoVue ${ }^{\mathrm{TM}} \mathrm{UV} /$ Visible spectrophotometer (GE Healthcare Ltd., UK). The DNA templates were adjusted to $100 \mathrm{ng} / \mu \mathrm{L}$ with ultrapure water.

\section{Primer design, amplification, and genotyping}

Microsatellite markers for $T$. granosa were characterized by screening the partial isotigs (ESTs) of our transcriptomic database (SRA052081) by 454 pyrosequencing. Putative EST-SSR markers were screened using the SSRHUNTER program (Li and Wan, 2005), which 
was set for detection of di-, tri-, tetra-, penta-, and hexa-nucleotide motifs, with a minimum of $6,4,3,3$, and 3 repeats, respectively. Primers flanking the microsatellites were designed by the Primer Premier 5.0 software (Premier Biosoft International, USA), and synthesized by Sangon Biotech Co. Ltd (Shanghai, China).

Polymerase chain reaction (PCR) amplifications were performed in a $20-\mu \mathrm{L}$ reaction mixture containing $0.5 \mathrm{U}$ rTaq DNA polymerase (Takara, Japan), 1X PCR buffer, $0.2 \mathrm{mM}$ dNTP mix, $2.0 \mathrm{mM} \mathrm{MgCl}, 0.25 \mu \mathrm{M}$ of each forward and reverse primer, and approximately 100 ng template DNA. PCRs were conducted in a thermal cycler (Mastercycler ${ }^{\circledR}$ pro S, Eppendorf, Germany) under the following conditions: initial denaturation for $5 \mathrm{~min}$ at $94^{\circ} \mathrm{C}$, followed by 35 cycles of denaturation for $45 \mathrm{~s}$ at $94^{\circ} \mathrm{C}$, the optimized annealing temperature (Table 1) for $45 \mathrm{~s}$, and extension at $72^{\circ} \mathrm{C}$ for $45 \mathrm{~s}$, with a final extension at $72^{\circ} \mathrm{C}$ for $7 \mathrm{~min}$. The PCR products were separated by electrophoresis on $8 \%$ nondenaturing polyacrylamide gel at $180 \mathrm{~V}$ for 3 to $4 \mathrm{~h}$, depending on the size of the amplification product, and visualized by ethidium bromide staining under UV light. A 20-bp DNA ladder (MBI Fermentas, USA) was used as a reference marker to determine allele size. Genotypes were determined as approximate allele sizes.

\section{Characterization of polymorphic EST-SSRs and sequence annotation}

After optimization of the annealing temperature, primer pairs that produced clear bands of the expected size were selected for polymorphism analysis. Polymorphisms of each SSR locus were evaluated using 30 T. granosa individuals. All polymorphic SSR-containing ESTs were searched against the NCBI non-redundant $(\mathrm{Nr})$ protein database and the Swiss-Prot database using BLASTx, with an E-value threshold of 1e-6. Gene names were assigned to each assembled sequence based on the best BLAST hit (the highest score).

\section{Statistical analysis}

The number of alleles, the observed $\left(H_{\mathrm{O}}\right)$ and expected heterozygosities $\left(H_{\mathrm{E}}\right)$, and the polymorphic information content (PIC) were calculated using CERVUS 3.0 (Kalinowski et al., 2007). Deviations from the Hardy-Weinberg equilibrium (HWE) for each locus were estimated using the Markov chain method by the online version of GENEPOP (http://wbiomed. curtin.edu.au/genepop/) (Rousset, 2008). All statistical significance levels were adjusted for multiple tests using sequential Bonferroni corrections (Rice, 1989).

\section{RESULTS AND DISCUSSION}

From a screen of 8805 ESTs that examined the length and guanine-cytosine content of the flanking regions, 246 primer pairs were successfully designed and used for validation of the amplification. After optimization of the experimental conditions, 157 primer pairs $(63.8 \%)$ showed clear and consistent amplification patterns. Among these EST-SSRs, 115 were found to be polymorphic in the 30 clam individuals tested, resulting in a polymorphic percentage of $73.3 \%$, which is similar to that reported by Dong et al. (2012) (76.5\%), but is significantly higher than that found by Zhou et al. (2013) (46.8\%).

Analysis of the 115 SSR-motif types showed that the most abundant repeat motifs were tri-nucleotides $(51,44.35 \%)$, followed by tetra-nucleotides $(30,26.09 \%)$, and di-nu- 
cleotides $(19,16.52 \%)$ (Figure 1). This is consistent with the results of Zhou et al. (2013), but not with those of Liu et al. (2012). As is the case in other bivalves, penta-nucleotides (8, $6.96 \%)$ and hexa-nucleotides $(7,6.08 \%)$ were the least abundant motifs. Among the SSR motifs, TA $(29.41 \%)$ and AT $(29.41 \%)$ accounted for more than half of the di-nucleotide repeats, while CAA $(9.80 \%)$ and TGT $(7.84 \%)$ accounted for most of the tri-nucleotide repeats. AAAT $(13.33 \%)$ and TTAA $(10.00 \%)$ were the two most abundant tetra-nucleotide motifs.

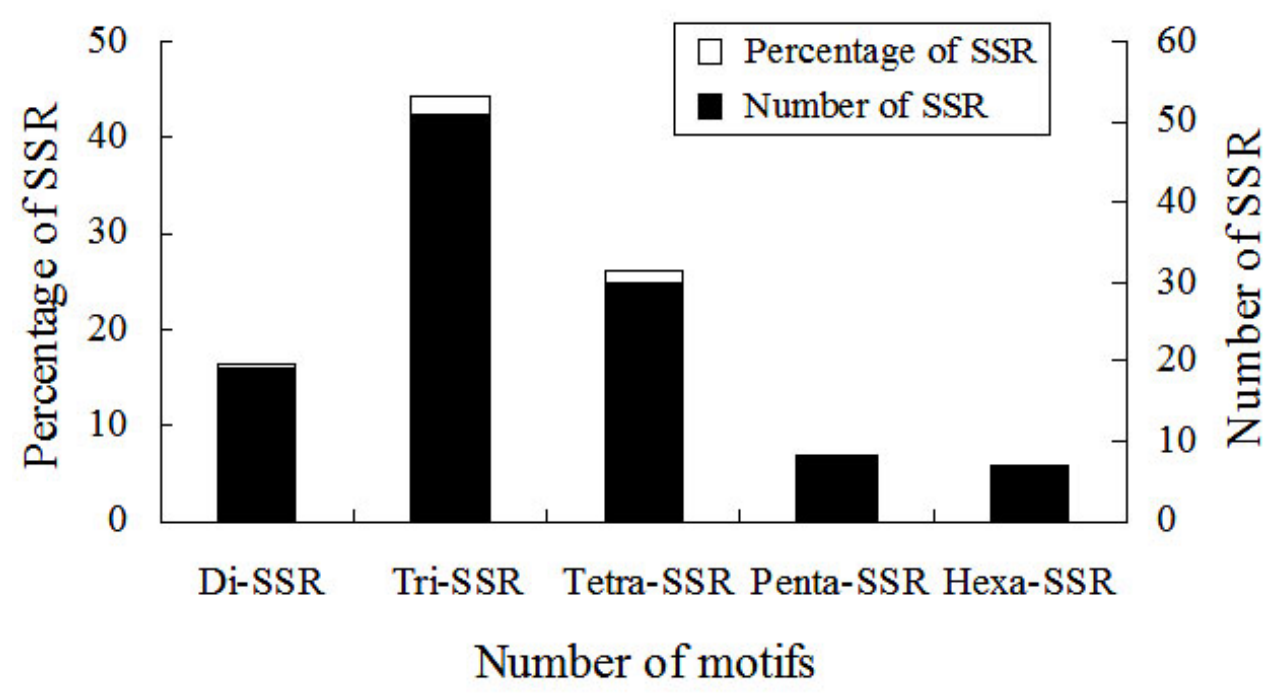

Figure 1. Distribution of 115 simple-sequence repeat (SSR)-motif types in Tegillarca granosa.

The number of alleles observed for the 115 loci ranged from 2 to 10 , with an average of 3.78 (Table 1), which is similar to previous results obtained from EST-SSRs (Dong et al., 2012; Liu et al., 2012). The $H_{\mathrm{O}}$ ranged from 0 to 1 , while the $H_{\mathrm{E}}$ varied from 0.040 to 0.799 . The average $H_{\mathrm{O}}(0.3885)$ across all loci was lower than the $H_{\mathrm{E}}(0.4338)$.

The mean PIC was 0.3834 , and ranged from 0.038 to 0.825 . There were 29 highly polymorphic loci (PIC $\geq 0.5)$ and 42 moderately polymorphic loci $(0.25<\mathrm{PIC}<0.5)$ that were suitable for population genetic analysis. Thirty-eight of the 115 loci deviated significantly from the HWE $(\mathrm{P}<0.01)$ after a Bonferroni correction (Table 1). This may be attributable to one or more factors, such as insufficient sample size, bottleneck effects, or even the presence of null alleles. Additionally, of the 115 polymorphic loci, $46(40 \%)$ were identified from transcript regions of known genes that serve as type I markers, and can be easily linked to a phenotypic trait of interest, making them valuable for functional diversity studies (Varshney et al., 2005). Furthermore, the presence of SSRs in the 5'-untranslated region (UTR) can affect transcription or translation, while SSRs in the 3'-UTR can affect splicing (Li et al., 2004; Lawson and Zhang, 2008).

Overall, the transcriptome data of T. granosa using pyrosequencing contained a large amount of accurate sequence information that was suitable for the rapid and large-scale discovery of EST-SSRs. A total of 115 novel polymorphic SSRs for T. granosa were identified in the present study, which will greatly enrich the SSR resources of this species and provide a valuable tool for further population genetic analyses, the construction of linkage maps, and MAS. 


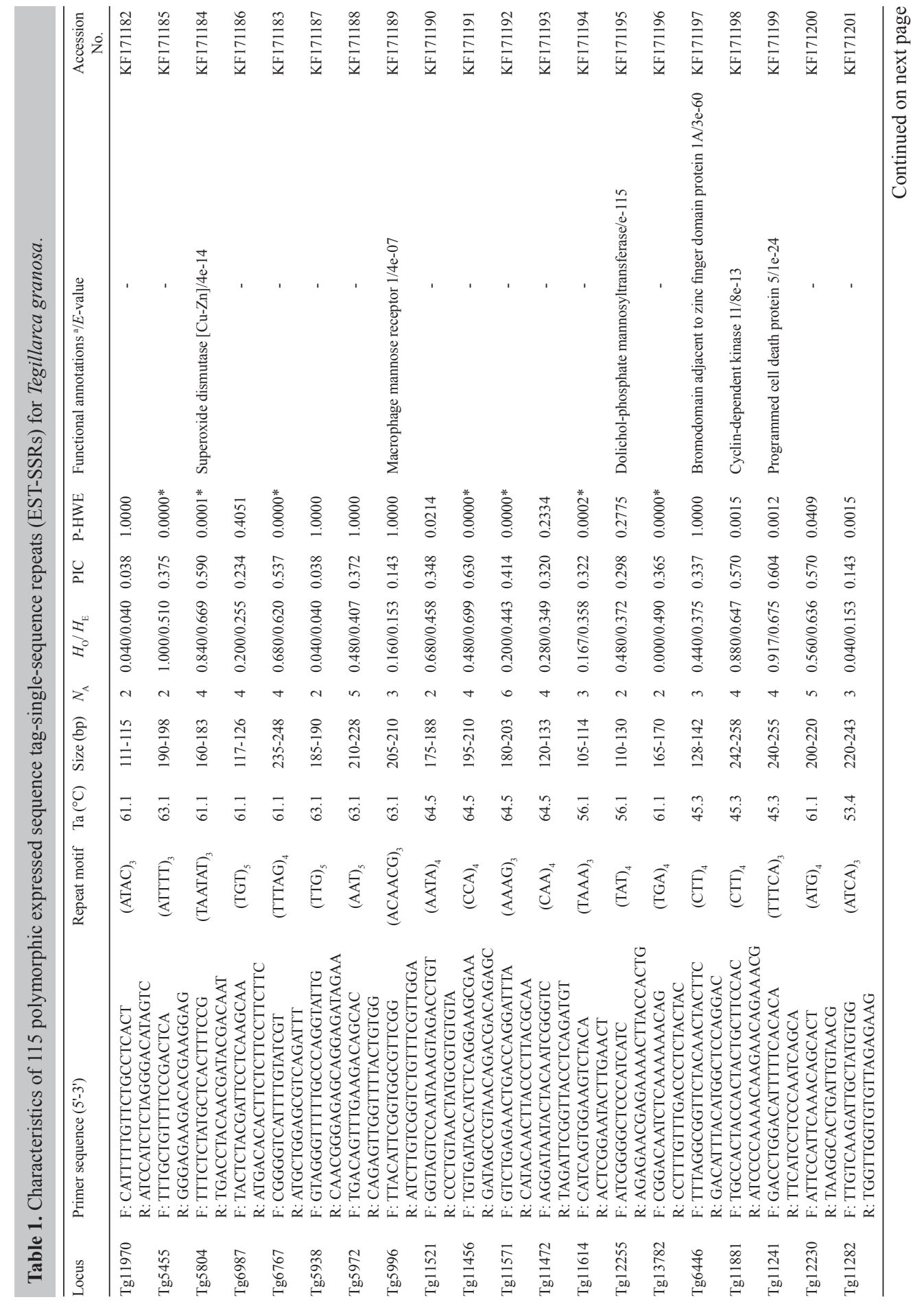


Y.H. Dong et al.

8982

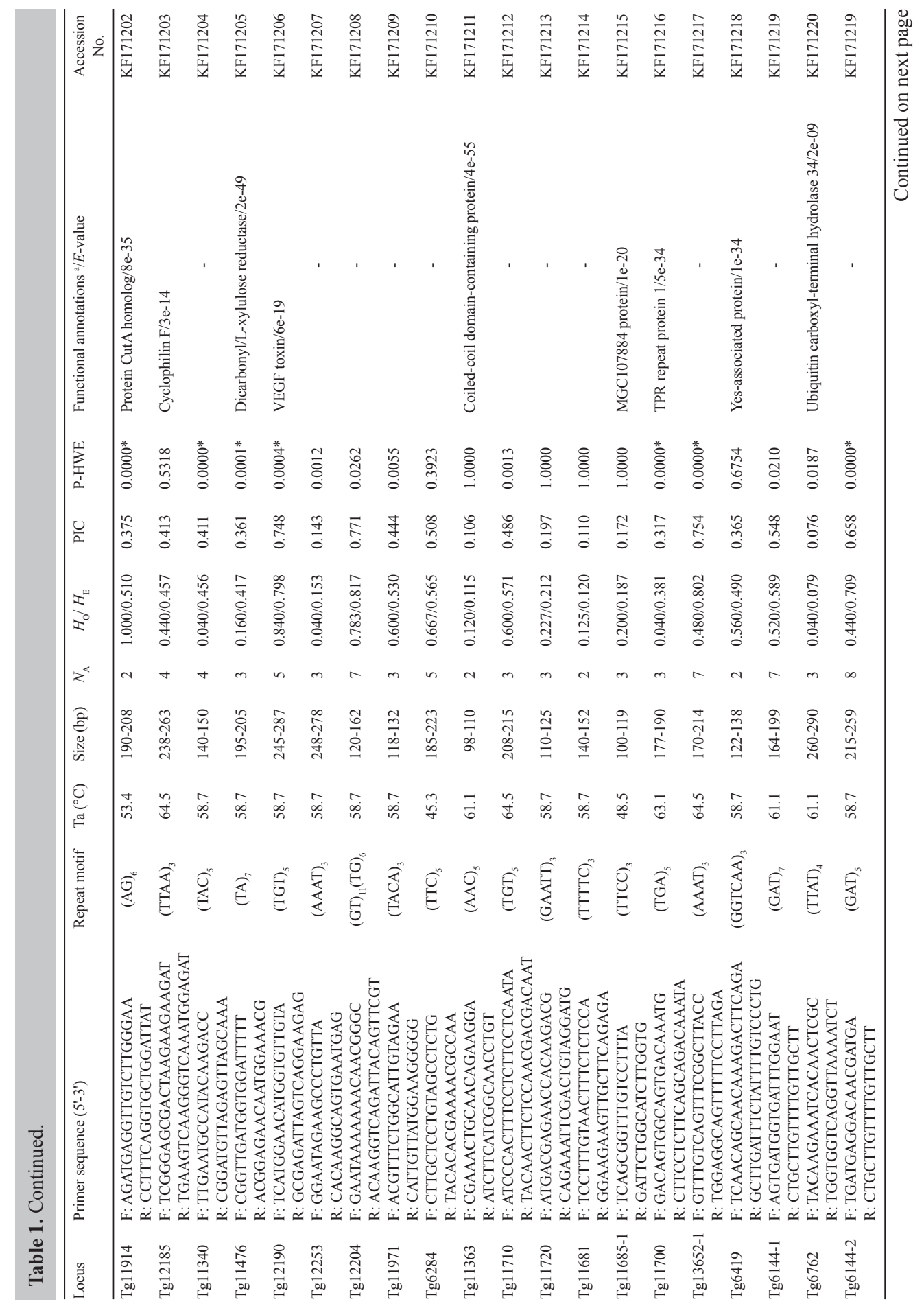

Genetics and Molecular Research 14 (3): 8977-8987 (2015)

CFUNPEC-RP www.funpecrp.com.br 


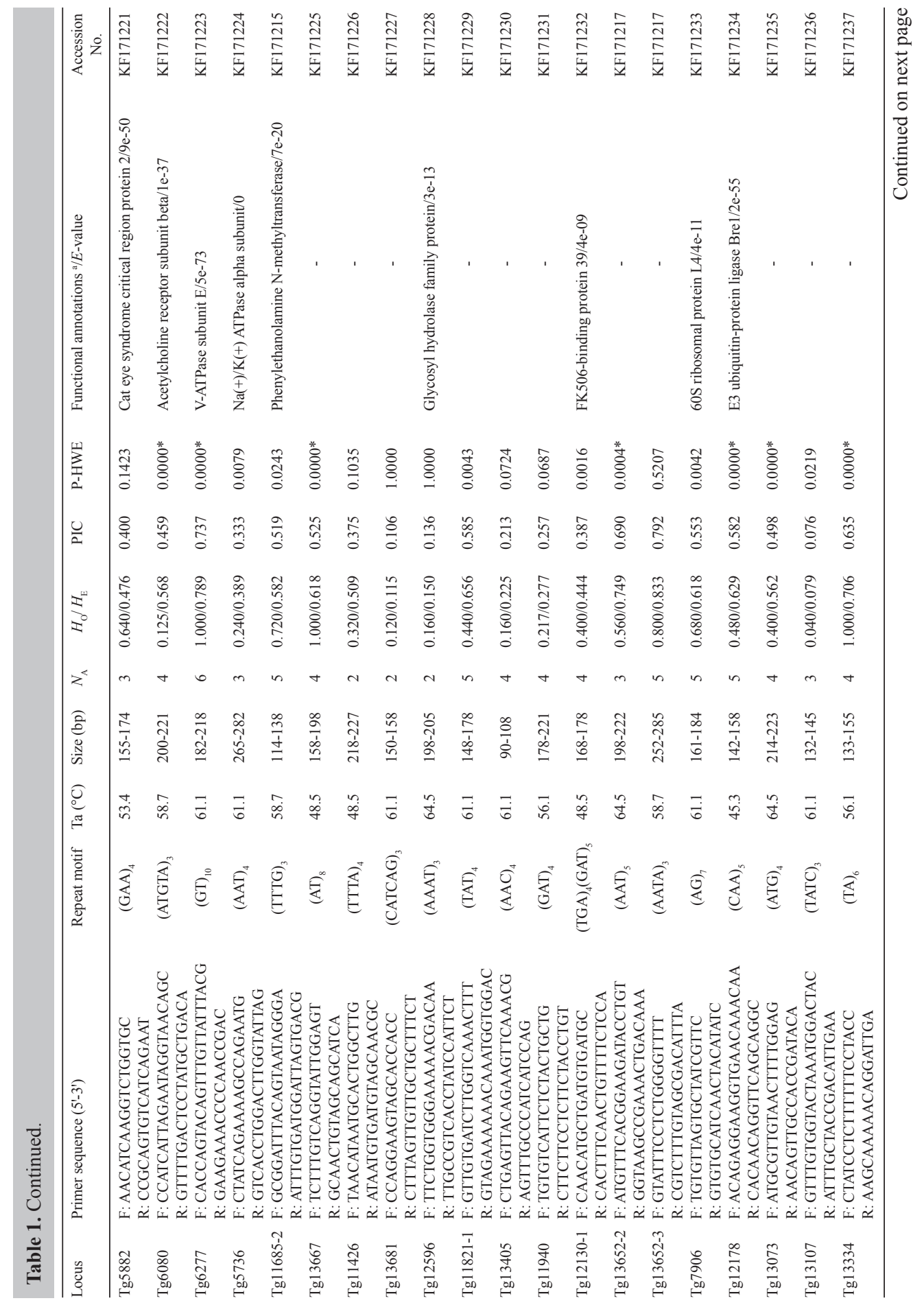


Y.H. Dong et al.

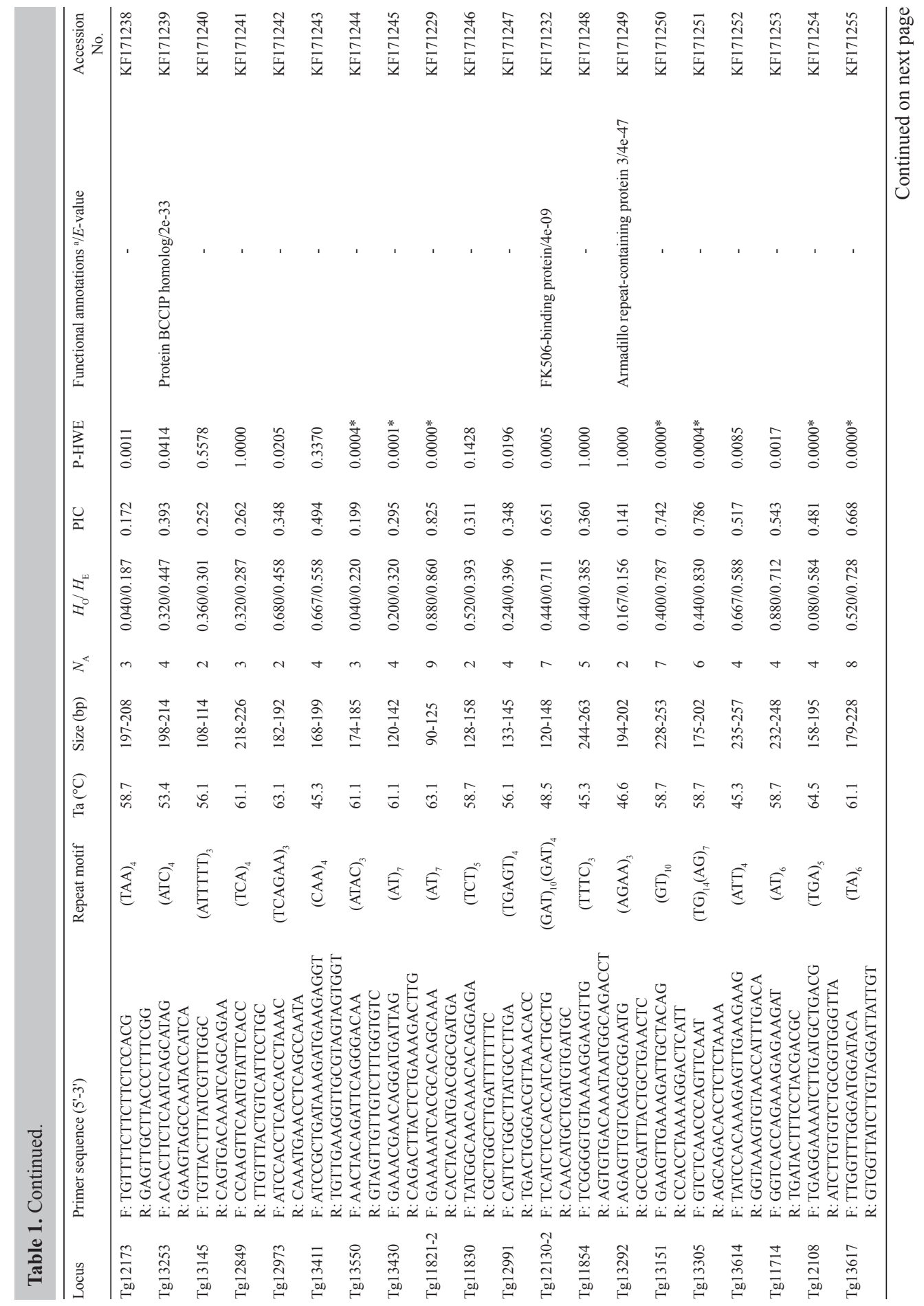




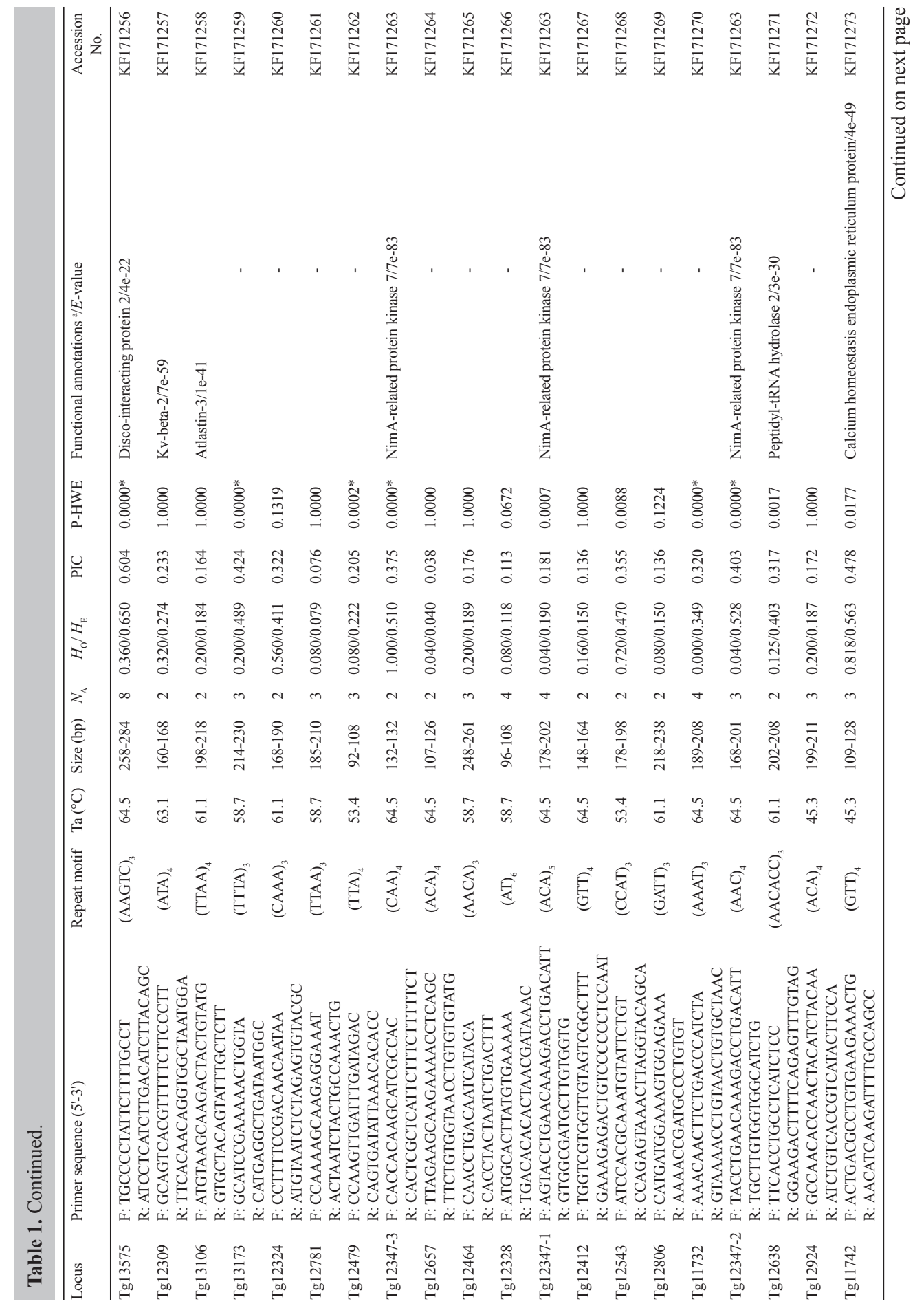


Y.H. Dong et al.

8986

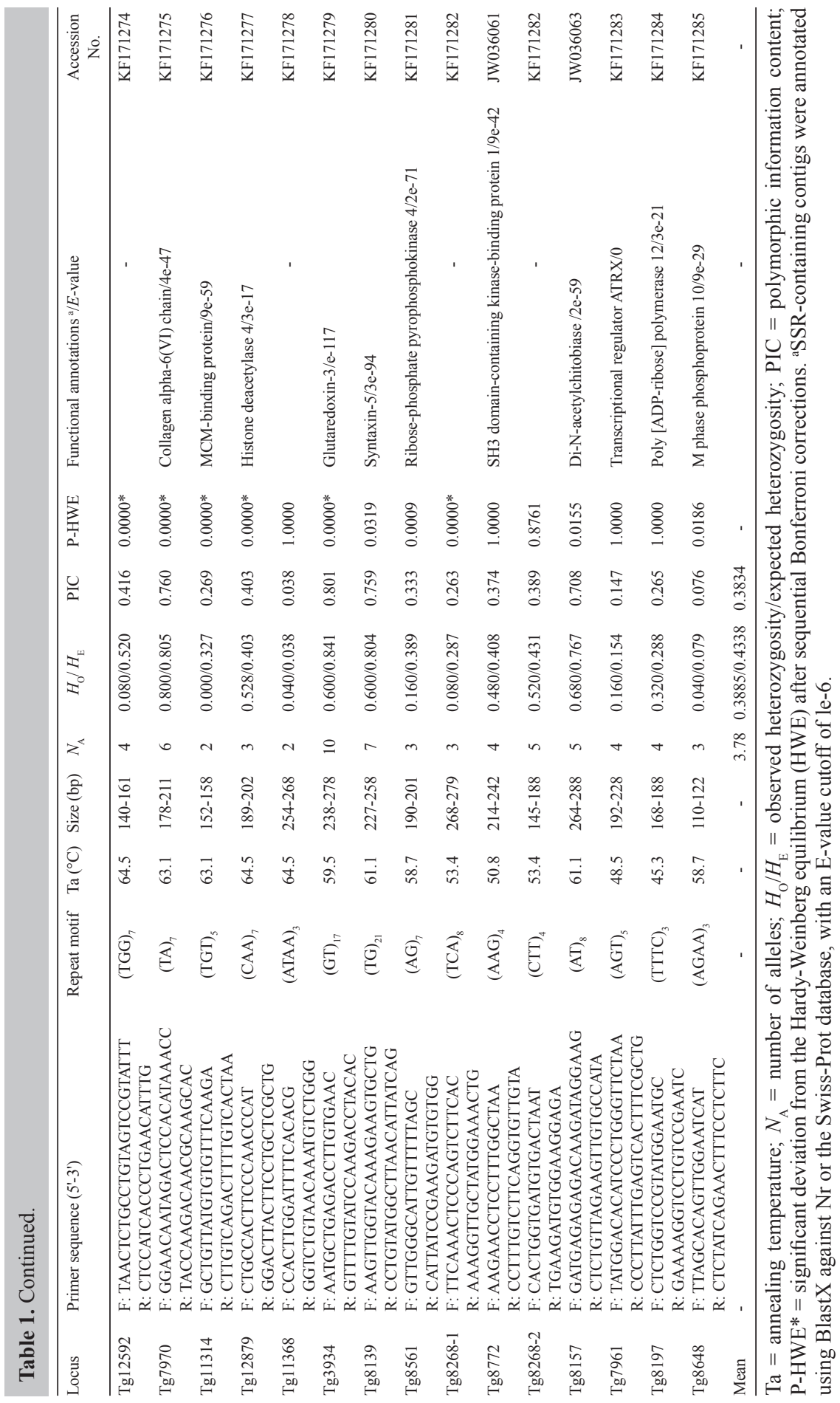




\section{ACKNOWLEDGMENTS}

Research supported by the National High-Tech "863" Project of China (\#2012AA10A400), the Zhejiang Major Program of Science and Technology (\#2012C129074), the Modern Agro-Industry Technology Research System (\#CARS-48), and Key Science Foundation of Zhejiang Province (\#LZ12C19001).

\section{REFERENCES}

Dong YH, Yao HH, Lin ZH, Zhang LL, et al. (2012). Characterization of 62 polymorphic EST-SSR markers in the blood clam (Tegillarca granosa) and their cross-amplification in Scapharca subcrenata. Conserv. Genet. Resour. 4: 991-997.

Dong YH, Wu GX, Yao HH, Lin ZH, et al. (2013). Characterization of 34 polymorphic EST-SSR markers in Tegillarca granosa and their transferability in Anadara craticulata. J. Fish. China 37: 70-77.

Duran C, Appleby N, Edwards D and Batley J (2009). Molecular genetic markers: discovery, applications, data storage and visualisation. Curr. Bioinformatics 4: 16-27

Gu XY, Zeng QG, You ZJ and Lin ZH (2008). Isolation and characterization of six microsatellite primers of Tegillarca granosa. Oceanol. Limnol. Sin. 39: 661-664.

Kalinowski ST, Taper ML and Marshall TC (2007). Revising how the computer program CERVUS accommodates genotyping error increases success in paternity assignment. Mol. Ecol. 16: 1099-1106.

Lawson MJ and Zhang L (2008). Housekeeping and tissue-specific genes differ in simple sequence repeats in the 5'-UTR region. Gene 407: 54-62.

Li Q and Wan JM (2005). SSRHUNTER: Development of a local searching software for SSR sites. Yichuan 27: $808-810$.

Li YC, Korol AB, Fahima T and Nevo E (2004). Microsatellites within genes: structure, function, and evolution. Mol. Biol. Evol. 21: 991-1007.

Liu B, Teng SS, Shao YQ, Chai XL, et al. (2012). Isolation and characterization of 39 novel polymorphic EST-SSR loci for the blood clam, Tegillarca granosa. Conserv. Genet. Resour. 4: 375-378.

Rice WR (1989). Analyzing tables of statistical tests. Evolution 43: 223-225

Rousset F (2008). Genepop'007: a complete reimplementation of the Genepop software for Windows and Linux. Mol. Ecol. Resour. 8: 103-106.

Varshney RK, Graner A and Sorrells ME (2005). Genetic microsatellite markers in plants: features and applications. Trends Biotechnol. 23: 48-55.

Zhou XL, Zhu JH, Dong YH, Lin ZH, et al. (2013). Development and comparative study of genomic-SSR and EST-SSR in Tegillarca granosa. Oceanol. Limnol. Sin. 44: 467-475. 